\title{
NEONATAL ISCHEMIC STROKE AS A COMPLICATION OF OLIGOHYDRAMNIOS AND PLACENTAL VASCULAR THROMBOSIS
}

\author{
Peeravit Anukulkijkul ${ }^{1}$, Mana Taweevisit ${ }^{1}$ \\ Department of Pathology, Faculty of Medicine, Chulalongkorn University, King Rama IV \\ Street, Pathumwan, Bangkok, Thailand.
}

Background and aims: Ischemic stroke is not rare in term and near-term neonates. The pathophysiology of neonatal stroke is complex. Its incidence in childhood is highest during the first month of life, likely reflecting specific risk factors related to uteroplacental problem.

Methods: We present two autopsy cases of premature newborn infants with brain infarction associated with oligohydramnios and placental vascular thrombosis. Cesarean section was done in both cases due to fetal distress.

Results: The first case was a 1-day-old male neonate born at 34 weeks' gestation. The patient was intubated owing to respiratory distress. The clinical status was deteriorated and he eventually died. Autopsy showed multiple foci of infarction involving cerebral white matter. The second case was a 1-day-old female neonate born at 36 weeks' gestation. The patient died due to severe hypoxia. Autopsy showed extensive infarction of both cerebral hemispheres. Oligohydramnios was detected in both cases. In addition, both placentas revealed fetal thrombotic vasculopathy, defined by the presence of thrombosis in chorionic plate and stem villous vessels of placentas leading to degeneration and eventual loss of capillaries in affected villi (Figure A).
Conclusions: Combined oligohydramnios and fetal placental vascular lesions appear to be a predisposing factor for some adverse neurological outcomes in neonates. Such cases illustrate why the placenta of preterm neonate should always be examined, especially in those patients who present with thromboembolic events of unknown origin, particularly in the brain.

\section{References:}

1. Taweevisit M, Thorner PS. 'Massive' Fetal Thrombotic Vasculopathy Associated with Excessively Long Umbilical Cord in a Stillbirth: Case Report. Pediatr Dev Pathol. 2010 Mar-Apr;13(2)112-5.

2. Redline RW, Ravishankar S. Fetal vascular malperfusion, an update. APMIS. 2018 Jul;126(7):561569.

3. Giacchetti L, De Gaudenzi M, Leoncini A, Ferrucci E, Pezzoli V, Albisetti M. Neonatal renal and inferior vena cava thrombosis associated with fetalthrombotic vasculopathy: a case report. J Med Case Rep. 2017 Aug $28 ; 11(1): 248$.

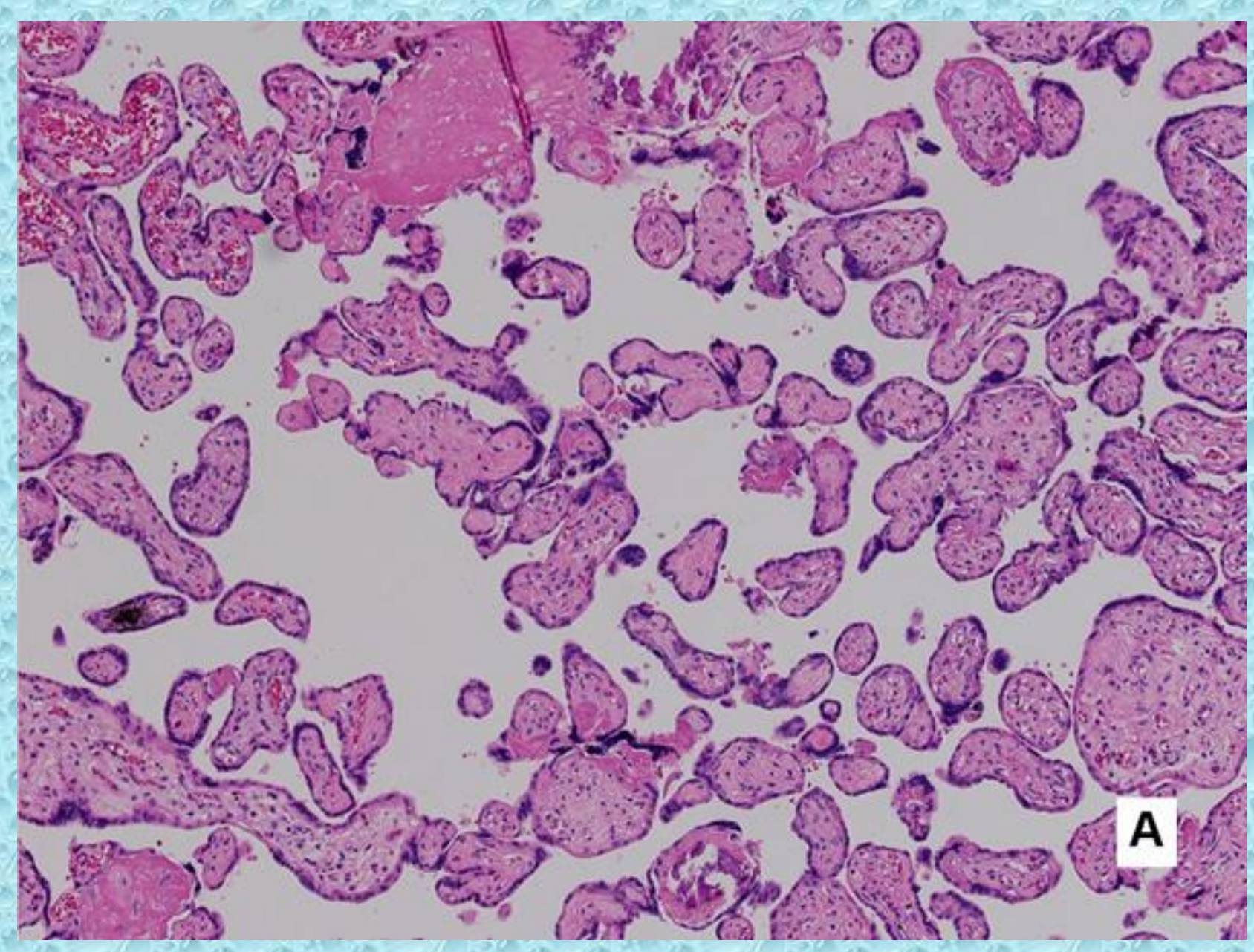

